\title{
How Taiwan Succeeded in Containing Its 2021 COVID-19 Outbreak
}

\author{
Catherine $\mathrm{Wu}^{1}$, Edward $\mathrm{Wu}^{1}$, Charles $\mathrm{Wu}^{1} \&$ Kun Chan $\mathrm{Wu}^{2}$ \\ ${ }^{1}$ Morrison Academy, Taichung, Taiwan \\ ${ }^{2}$ Wu Kun Chan Clinic, Miaoli, Taiwan \\ Correspondence: Kun Chan $\mathrm{Wu}, \mathrm{Wu}$ Kun Chan Clinic, Miaoli, Taiwan. E-mail: \\ wupedhanwupedhan@gmail.com
}

Received: December 1, 2021

Accepted: January 26, 2022

Online Published: Janaury 31, 2022

doi:10.5539/ass.v18n2p1

URL: https://doi.org/10.5539/ass.v18n2p1

\begin{abstract}
The severe acute respiratory syndrome coronavirus 2 (SARS-CoV-2), or coronavirus disease-2019 (COVID-19), emerged in December 2019 and has since then progressed into a global pandemic (Lai et al., 2020). However, the Taiwan model helped Taiwan contain the COVID-19 epidemic successfully for more than one year (Wu, 2020). Unexpectedly, sporadic cases began to emerge late April 2021, causing a large-scale COVID-19 outbreak in Taiwan (Kao, Shuhua, et al., 2021).

With the help of technology and reinforced border control, level 3 alert, accessible healthcare system, contact tracing, and quarantines, Taiwan's Central Epidemic Command Center contained the outbreak successfully within two months with the cooperation of the citizens. After the swift containment of the COVID-19 outbreak in Taiwan, there were significantly fewer locally transmitted COVID-19 cases, and the government and medical care units had become less weary. These measures to contain the outbreak helped Taiwan substantially by buying time to deploy against COVID-19, which is still a worldwide pandemic. Through analyzing Taiwan's actions taken in containing an ongoing outbreak of COVID-19, better frameworks can be designed for other countries to decelerate the spread of COVID-19 or future emerging respiratory infectious diseases.
\end{abstract}

Keywords: COVID-19, outbreak, pandemic, SARS-CoV-2, Taiwan model

\section{Introduction of Taiwan's First Large-Scale Outbreak of Coronavirus Disease-2019 (COVID-19) in 2021}

In December 2019, a brand new strain of virus came out to the world: the severe acute respiratory syndrome coronavirus 2 (SARS-CoV-2). Because this contagious virus causes asymptomatic infection, early detection is practically impossible; by the time it is detected, the disease-COVID-19-will be critical and often fatal. On top of that, nobody has adaptive immunity against it, and there is currently no effective curative medicine for it (Hu et al., 2020; Cascella et al., 2021).

These characteristics of COVID-19 led to the difficulty in containing this disease when it comes to an outbreak, hence its consistent prevalence across most nations from its inception to the present (COVID-19 Map, n.d.). To make containment more challenging, the virus has since then mutated into Alpha, Beta, Gamma, and Delta variant strains (Tracking SARS-CoV-2 variants, n.d.).

Unlike many other countries, the Taiwan model succeeded in fighting against COVID-19 for more than one year, and there was even no local transmission between April and December 2020 (Chang, 2020; Wu, 2020). The Taiwanese lived a relatively normal life while maintaining their normal social activities during this period. The government even encouraged people on this island to attend any kind of activities, including events involving large social gatherings such as baseball tournaments, religious pilgrimages, and concerts (Ministry of Health and Welfare, 2020). Moreover, Taiwan achieved an economic record with a growing GDP (3.12\% growth in 2020 and an estimated 5.88\% in 2021) and stock market (Department of Accounting, Executive Yuan (DGBAS), 2005; Taiwan Stock Exchange FACT BOOK 2021, n.d.). According to a national survey conducted by the Ministry of the Interior in 2020, many people felt satisfied with the anti-epidemic decisions and policies made by the government during this period (National Current Affairs Polls, 2020).

Dealing with COVID-19 affairs for more than one year, most people had naturally learned to build some essential anti-epidemic habits and behaviors, and they gradually chose to live relatively normal lives due to the well-controlled epidemic (Wu, 2020). 
However, for a series of careless and unexpected mishaps, sporadic cases of COVID-19 began to be found in late April 2021 (Kao, Shuhua, et al., 2021; Ministry of Health and Welfare, 2020).

First, a COVID-19 case - the victim being a pilot of a cargo aircraft of China Airlines-was discovered. This infectious event spread to cohabiting family members and related contacts. In addition to the infected pilot, a cluster of infections developed in the quarantine residence of China Airlines flight crews in Taoyuan Novotel Hotel. After analyzing the data of antibody tests and gene sequences of all patient samples, the Central Epidemic Command Center (CECC) commented that there might be an "interactive infection link" within the two clusters ("They are all", 2021).

Ultimately, there were a total of 37 China Airline-related and Novotel Hotel-related COVID-19 cases though the exact sources of infection remain unclear. Soon after the two events, the disease spread in clusters, and the domestic cases ascended in just a short time (Kao et al., 2021). Following these two clusters were the Yilan Arcade Cluster (13 cases), Lions Club Cluster (34 cases), Wanhua Tea House Cluster (more than 215 cases), Religious Pilgrims Cluster, Changhua Fruit Vendor Cluster (112 cases), and more. All these COVID-19 clusters accumulated only in a span of a few weeks and caught Taiwan off guard (Kao, Shuhua, et al., 2021; Ministry of Health and Welfare, 2020).

At the beginning of this outbreak, most cases could be clearly traced to their infectious sources with strict contact tracing and quarantine government policies (including tracing patients' digital footprints near the confirmed cases). Then, by analyzing flow charts and other data, the CECC could easily track the cases and their relationships with others, allowing officials to make intervention decisions appropriately. However, in just a short time, the conditions were exacerbated by the larger-scale Taipei and Miaoli outbreaks. Overwhelmed by these sudden escalations of epidemic events, patient tracing proved more difficult, which produced growing cases with unknown infectious sources (Kao, Shuhua, Yuxin, Yuting, et al., 2021; Ministry of Health and Welfare, 2020).

Luckily, investigators realized that most cases with unknown sources are at their initial disease stage, evident through their low Ct value of PCR test results (News, 2021; Tan, 2021). However, this large-scale outbreak concerned the public, prompting the anti-epidemic affairs to become urgent.

Again, through the swift implementation of aggressive interventions and policies of Taiwan's CECC, the COVID-19 epidemic eased within the next two months, and it remains at a shallow epidemic plateau (Kao, Shuhua, Yuxin, Yuting, et al., 2021). Taiwan then adjusted its anti-epidemic status to level 2 alert on July 27, permitting more indoor and outdoor gatherings (Ministry of Health and Welfare, 2020; News, 2021b).

Taiwan successfully contained the outbreak without imposing a lockdown. This article presents the methodology and the characteristics of Taiwan's model that contributed to Taiwan's success in combating the 2021 COVID-19 outbreak (COVID-19 - Taiwan, n.d.; Kao, Shuhua, et al., 2021; Kao, Shuhua, Yuxin, Yuting, et al., 2021).

\section{Methods}

The content of this article was mainly gathered from the information released from the CECC and the Centers for Disease Control (CDC) in Taiwan and statistical data from the Center for Systems Science and Engineering (CSSE) at Johns Hopkins University (JHU), the US CDC, and the World Health Organization. The paper also includes the authors' observations when attending conferences, personal interviews, and seminars on COVID- 19 . Other sources were from press reports and websites on COVID-19 provided by the health authorities.

\section{Reasons for Taiwan's COVID-19 Outbreak}

During Taiwan's stable, COVID-free condition in mid-2020, people in Taiwan had regular meetings, gatherings, religious activities with nearly half the people roaming in public without a mask. However, Taiwan still executed its border control by placing overseas immigrants into quarantine for two weeks. This policy yielded successful results as there were no positive domestic COVID-19 cases in the hospitals of Taiwan (Ministry of Health and Welfare, 2020).

As the good records went on, a feeling of complacency developed among citizens and even the government. For some imperceptible reasons, several cases showed up, and a new outbreak surged. Most people thought that the tipping point of this outbreak was the carelessness of the government to change the policy of quarantine requirements for immigrant pilots from a 14-day period to a 3-day period on April 1, 2020. This epidemic prevention flaw on top of the loose management of quarantine hotels for immigrant flight crews was generally thought to have directly led to the first clusters (Tan, 2021). About one month after the change of pilots' quarantine policy, the virus insidiously spread to the community and eventually made its way to Wanhua's "tea houses"-adult entertainment venues (Kao, Shuhua, Yuxin, Yuting, et al., 2021). The tea houses in Wanhua are 
usually crowded with people in narrow streets where people sing, drink, and frequently contact with each other indoors, undoubtedly making these tea houses large superspreaders. In addition, clusters of COVID-19 infections formed the first event of the largest domestic outbreak ever in Taiwan. Unfortunately, the outbreak spread and surged rapidly.

\section{Taiwan's Principal Reaction to This Epidemic (Figure 1)}

\subsection{Reinforce the Border Control Policy}

The first step for Taiwan's containment of this outbreak is to check and mend all the flaws of the anti-epidemic affairs immediately. Taiwan's government noticed that they carelessly made some mistakes. An obvious example is the loose quarantine policy of flight crews; a then aseptic island, Taiwan must have incurred the SARS-CoV-2 virus from abroad (Kao, Shuhua, Yuxin, Yuting, et al., 2021). Soon after this outbreak, Taiwan's CECC adjusted its policies to let flight crews undergo a five-day home quarantine (PCR tests are required on the last day) and practice a nine-day enhanced self-health management (named the "5+9 policy"). Since July 1, the policy has even changed to the 7+7 mode ("CECC adjusts quarantine measures", 2021; Ministry of Health and Welfare, 2021).

Aside from flight crews, Taiwan has set travel bans for normal passengers and flexibly adjusted its extent according to the condition of global epidemics since 2020 (Wu, 2020). During this outbreak, Taiwan still executed its strict border control policies. For example, residents or travelers who obtained special permits for entering Taiwan from abroad must show proof of a negative PCR test from the last $72 \mathrm{~h}$ issued within three days to qualify for boarding airplanes after December 1, 2020. Considering the worldwide surge of the delta strain COVID-19 since July 2021, all arriving travelers are required to take PCR tests upon arrival at the airport or the port in Taiwan to prove their non-infection status of COVID-19 (Disease Control Agency, 2021).

After entering Taiwan's customs, all immigrant passengers are required to take well-trained qualified quarantine vehicles to Epidemic Prevention Quarantine Hotels or quarantine facilities to complete their mandatory quarantine for 14 days. Before the end of their quarantine, all passengers will also undergo PCR tests mandatorily, and only those who test negative can be released from quarantine. For all released travelers, an additional seven days of self-health management are recommended, which means that they can live normal lives but with intensive caution of mask-wearing and social distancing (Ministry of Health and Welfare, 2021). Undoubtedly, those who have positive test results will be sent to the hospital for further isolation and treatment.

\subsection{COVID-19 Level 3 Epidemic Alert in Effect Around Taiwan}

There are four epidemic warning levels in Taiwan in reaction to the severity of the COVID-19 outbreak. The definition of level 3 epidemic alert is that there are more than three cluster infection cases in a week or over 10 cases of unknown source domestic infection within one day (News, 2021b). As the epidemic surged, on May 19th 2021, the fifth day after the Wanhua Tea House Cluster outbreak, Taiwan's CECC raised the national COVID-19 alert to level 3 after the country recorded over 267 newly confirmed locally transmitted COVID-19 cases (Lee, 2021; Ministry of Health and Welfare, 2020).

Some important related societal measures of Taiwan's level 3 alert are listed below:

Wear masks outdoors all the time with recommended social distancing; limited indoor gatherings with no, more than five people; all major leisure and business venues are closed, with the exception of essential services such as police departments, hospitals, and government buildings; masks and social distancing are required for any remaining functioning businesses or venues; avoid unnecessary movement, activities, or gatherings; indoor food and beverage-providing is restricted (Ministry of Health and Welfare, 2020).

\subsection{Accessible Healthcare System}

In Taiwan, the enrollment of health insurance is compulsory for all citizens and legal residents. Approximately 99.6\% of the population have joined the National Health Insurance (NHI), and about $93 \%$ of healthcare providers are contracted with the NHI. Under the NHI's design, healthcare premiums and copayments are affordable to most people. This makes people habitually seek medical services when they feel sick. Upon visiting the doctors, patients have to show their health cards for registration, which helps the health practitioners to retrieve their TOCC (travel, occupation, contact, cluster) data from MediCloud needed for COVID-19 determination. Thus, during the times of the epidemic, medical professionals can easily track or reach potential patients, which took a pivotal stand in fighting against this outbreak. When there are confirmed cases, all medical facilities are obligated to report to the CECC for further action (Central Health Insurance Agency, 2020). 


\subsection{Persevering Contact Tracing with the Use of Smart Technology}

In early 2020, Taiwan's CECC invented a set of strict contact tracing systems for COVID-19 (Wu, 2020).

During the outbreak in 2021, the CECC upgraded the contact tracing system (Department of Disease Control, 2020a).

\subsubsection{Border Control}

From early 2020, passengers are required to activate Taiwan's telecom phone number when immigrating to Taiwan. Immigrant passengers also need to text personal declarations to the "Entry Quarantine System"; the information will then be integrated into the 14-day "anti-epidemic tracking system" and the tracking alarm "electronic fence system" to conduct electronic tracking. These systems integrate the national data from Customs and Immigration, Household Registries, NHI, civil affairs units, public health units, and district police forces to care for and monitor people in home isolation and quarantine. By way of GPS tracking, travelers in quarantine will be found and fined if they do not stay within the permitted hotels or facilities for quarantine requirements (Quarantine System for Entry (Aircraft version)-Ministry of Health and Welfare, n.d.; Wu, 2020).

\subsubsection{NHI MediCloud System}

The National Health Institute in Taiwan has built a patient-centered cloud-based inquiry system (MediCloud system) for medical care information since 2016. This inquiry system uses a safe VPN internet to secure patients' privacy. When people visit doctors, they need to register their NHI health cards to medical units. By using the patient's NHI health card, doctors in hospitals or clinics can retrieve his/her data from the MediCloud system. Many important individual items and data of patients seeking medical care at different healthcare facilities are stored on the platform (Central Health Insurance Agency, 2020).

Not long after this outbreak, the Taiwan government then allowed the National Health Insurance Administration to coordinate with the National Immigration Agency to incorporate individuals' past 21-day travel history into their NHI health cards. Using this method, remarks are placed in the NHI MediCloud for those who are kept in quarantine, aircraft crew members, medical staff, residents, and workers of long-term care units. Through this invention, the MediCloud system became a regular platform for medical institutions to check patients' TOCC history. By using the NHI health card, front-line medical personnel can easily assess infection possibilities of patients by jointly examining their medical records and travel history (Central Health Insurance Agency, 2020; Disease Control Agency, 2020a).

\subsubsection{QR-code Real-Name Registration System}

Since May 19th 2021, the government has developed an easy-to-set-up digital system to let stores, public institutes, or markets make their individual QR codes. When entering a facility, citizens and foreigners alike are obligated to register their footprint by using the mobile phone to scan the QR code to conduct real-name registration. These personal digital footprints were collected and stored by telecom companies in cloud databases and prohibited to be released unless a person is under contact tracing (News, 2021c).

\subsubsection{Highly Effective Contact Tracing Investigation System}

At the early stage of this worldwide pandemic in early 2020, the contact tracing investigation system played an important role in effectively containing COVID-19 cases in Taiwan (Wu, 2020).

During this outbreak, Taiwan reinforced and further intensified this contact tracing investigating system. Whenever there is a new COVID-19 case, strict contact tracing policies will be executed immediately by the CECC in cooperation with local authorities (Health Bureau). With the aforementioned help of technology, the big data of confirmed and suspected cases of COVID-19 become easy to be placed under scrutiny by investigators. In addition, when executing epidemic tracing, the data collected from GPS or real-name registration can help the analysis and tracing of the footprints of potential confirmed or suspected contacted cases (Disease Control Agency, 2020a).

\subsubsection{Cooperation of the Health Bureau with the CECC}

During the COVID-19 outbreak, the Health Bureau in every city of Taiwan has its public power and is responsible for conducting contact tracing. Once local COVID-19 affairs become congested or the condition becomes too complicated, local officials will contact the CECC for advanced assistance of resources and personnel from the central government. In fact, during this period of containment in June and early July of 2021, there were three times in which the CECC set up incident command posts for cluster infections in electronic companies in Miaoli County, Pingtung County, and Huannan Market in Taipei City (Ministry of Health and Welfare, 2020). 


\subsection{Quarantine Enforcement}

To contain COVID-19, Taiwan follows the principle of "super early response" for quarantine, in which confirmed patients will be admitted to the hospital for isolation therapy immediately upon diagnosis. Those identified as potential contacts of COVID-19 will be notified of home quarantine or self-health management for 14 days according to the degree of contact, and such decisions are mandatory (Disease Control Agency, 2020a).

\subsubsection{Swift Isolation of All Confirmed Cases and Quarantine of All Possible Cases}

This is a provoking key factor for containing this outbreak. All the confirmed cases will be placed into the hospital for isolation and treatment until PCR tests prove negative. All suspected cases are placed into home quarantine for two weeks. The CECC cooperates with the local governments to expand the number of quarantine hotels to assist members of the public who require hotel quarantine. Through the "Wanhua Tea House Cluster" and its subsequent hotspots, people visiting these entertainment venues usually had close contact with confirmed cases, but they usually did not like to disclose their true contact history, which is an obstacle for patient investigation and thus affected affairs in contact tracing and quarantine (Kao, Shuhua, Yuxin, Yuting, et al., 2021).

Under the announcement of level 3 epidemic alert, the CECC swiftly forbade the operation of such kinds of entertainment venues along with the "eight specialized service occupations," where people usually sang, drank, and gathered. Confirmed cases were effectively isolated, and possible contacts were quarantined; on the other hand, those who conceal the truth of contact history are heavily fined (Ministry of Health and Welfare, 2020).

\subsubsection{Strong Care Support for Those Under Quarantine and Isolation}

People during quarantine or isolation at qualified facilities will receive care and support phone calls from the local government. They will also get a daily automatic message sent by the CECC inquiring about their health status; travelers in quarantine must report by texting back. All these methods facilitate the government's involvement in life, mental, and medical support of people during quarantine or isolation (Disease Control Agency, 2020a).

\subsection{3 "Anti-epidemic Tracking System" and the Tracking Alarm "Electronic Fence System"}

People in quarantine or isolation should have a Taiwan telephone number and should always have access to the Internet. The government will check the signal randomly (anti-epidemic tracking system). If they disconnect the signal or leave the place of reported location, then the authorities and police will know and come to investigate (electronic fence system). If they break the quarantine rules by leaving the confines of their quarantine hotel, they will be punished with heavy fines.

\subsection{Tests}

Because of the easy availability of medical consultation, most tests, including rapid antigen tests or PCR tests, were given to the identified potential contacts. Under such conditions, most decisions for tests were made only by professional medical practitioners. In this way, the resources of tests were efficiently applied to those highly suspected of COVID-19.

Only when hotspots of COVID-19 outbreak occur, a large frontline temporary test center would be set up to help determine the confirmed or suspected cases and further help intervene in containment affairs of COVID- 19 . These frontline command experts and their resources of large-scale tests came from the need and requested support from the local health bureau to the CECC. The main principle applied to contain COVID-19 hotspots, especially the affairs of large-scale contact tracing and tests, was on-site triaging (Ministry of Health and Welfare, 2020). 


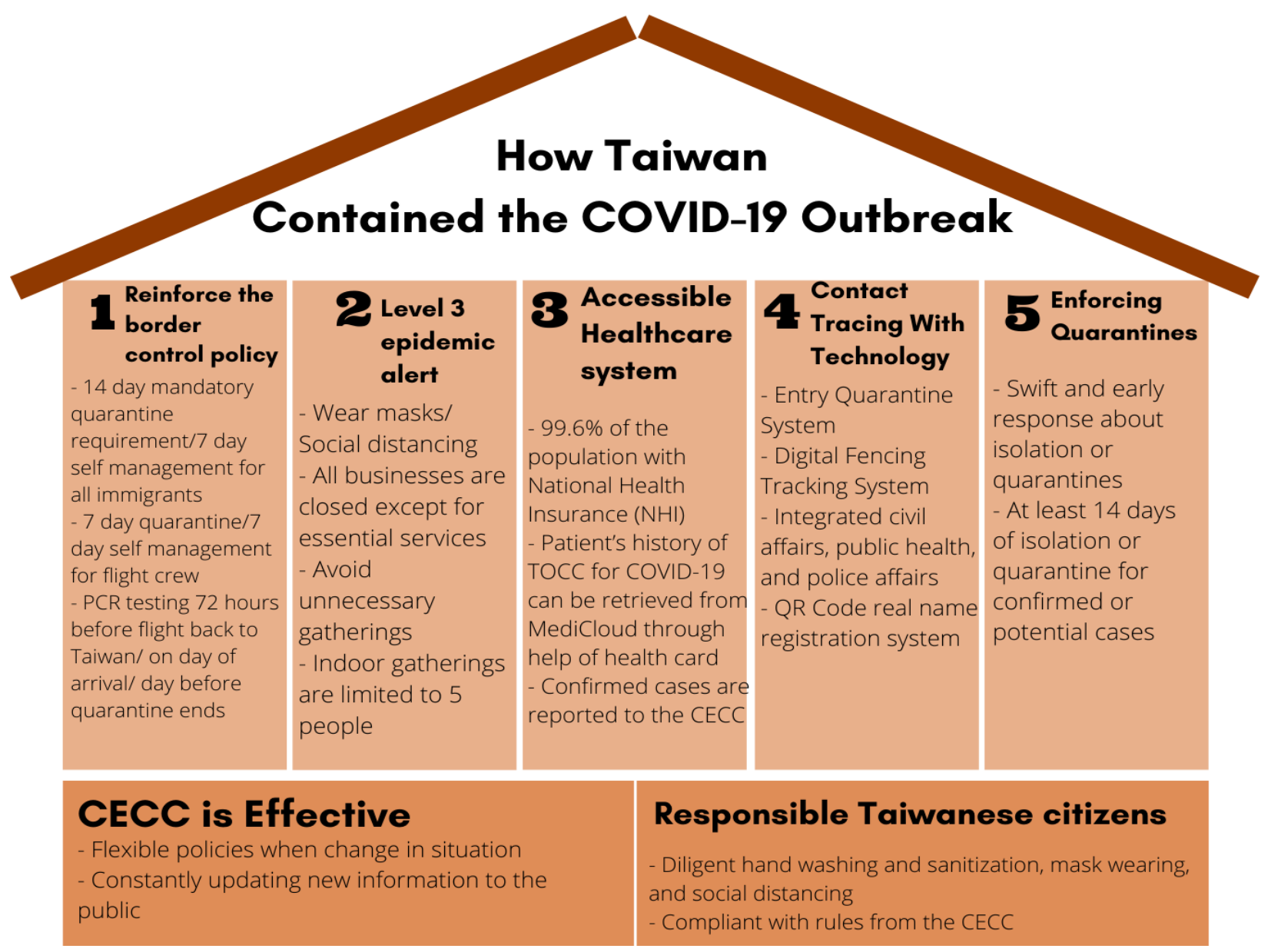

Figure 1. Taiwan model to contain the 2021 COVID-19 outbreak

\section{Discussion}

\subsection{Affairs of COVID-19 Containment Are Multifaceted and Need Timely Adjustment}

Since the COVID-19 pandemic in 2020, many countries struggled in fighting against spikes of the outbreak, but Taiwan worked effectively against COVID-19 for more than one year (Wu, 2020).

Under such conditions, people in Taiwan, including the government, began to have a noticeably more relaxed attitude toward the issue and undermined the danger of the disease. This is why the border control and hotel quarantine measures of Taiwan became looser and led to the largest outbreak of COVID-19 in Taiwan ever ("The global anti-epidemic "myth is shattered"' 2021).

As the crisis of the COVID-19 epidemic seemed to spread, cases of COVID-19 still surged even though the government conducted strict and proper policies immediately and was conscientious for a period of time. With increasing number of clusters, the country was soon filled with fear and complaints, and the government in great distress (Ministry of Health and Welfare, 2020). Some people even debated on TV, social media, and various other platforms whether the Taiwan model works (China Times News, 2021; Hongji, 2021).

Several months after the successful containment of this outbreak and after the declaration of level two alert and promulgation of some economic stimulation policies by the government, people in Taiwan went outdoors and gathered again (Economic Daily, 2021).

All these reflected the truth that policies for containing the COVID-19 outbreak are complex and should take many affairs into timely consideration such as public opinion, social-economical activities, medical capacities, and even politics (Straight to the point of care, 2021; Weinstein, 2021).

\subsection{CECC's Leadership with Its Efficiency and Transparency Could Help (Figure 1)}

Taiwan's CECC is authorized by the Infectious Disease Control Act to mobilize all resources and personnel from 
Taiwanese social departments ( $\mathrm{Wu}, 2020)$. The CECC has the power to implement many mandatory policies for the people, which allows for swift and efficient problem-solving and decision-making. During the anti-epidemic process, the CECC has its big policy, but they regulate and update methods timely, which they call rolling regulation.

The CECC in Taiwan also makes the anti-epidemic information and policies transparent (COVID-19 - Taiwan, n.d.; Kao, Shuhua, Yuxin, Yuting, et al., 2021; Wu, 2020).

The CECC and its experts reveal information through face-to-face press conferences every afternoon, which are live-streamed and broadcast to the people on TV. The nationwide information then spreads to the public by use of press, Internet, social media, or emails. This form of transparency allows citizens to be aware of any updates in government policies.

\subsection{Good Cooperation of the Citizens with the CECC (Figure 1)}

Taiwan's CECC promulgates policies according to all changing situations. Most citizens in Taiwan know the importance of precautions to prevent infections after one year of the epidemic and the education from the CECC (Disease Control Agency, 2020a).

Amazingly, most people on this island abide by these rules. Almost all people wear their own masks indoors or outdoors since this outbreak. They even monitor the mask-wearing behaviors of other individuals on the street. Moreover, almost all stores execute real-name registration and take the temperature at the store's front door. Sanitizers for disinfection are everywhere in public. People know and take for granted the behavior of handwashing, mask-wearing, and social distancing. Restaurants are ordered not to allow indoor dining, which they complied with. One important reason Taiwan came this far in the fight against COVID-19 is the high-quality citizenship and social responsibility.

\subsection{Level 3 Epidemic Alert}

To contain COVID-19, many countries chose to lock down when an outbreak occurs. While it might be effective, it also comes at a price. Given that people worldwide are eager to live a life of relative freedom, Taiwan never locked down but only announced a level 3 epidemic alert to the citizens during this outbreak. Eventually, Taiwan showed the world that enforcing hygiene, handwashing, social distancing, and quarantine or isolation of specific persons is effective in combatting the epidemic.

\subsection{Tests}

Many societies, including Taiwan's, have disputed the necessity of massive tests. This is because constant and massive testing of COVID-19 is expensive. In Taiwan, most decisions made for COVID-19 tests were after contact tracing or evaluation by professional medical staff. By reserving tests for specialized occasions, COVID-19 tests in Taiwan were carried out more efficiently and less resource-consuming.

\subsection{Vaccinations}

Evidence shows that the COVID-19 vaccine can protect people from getting infected and even plays a role in herd immunity (CDC, 2020). However, at the time of this outbreak, the vaccination rate of COVID-19 per 100 Taiwanese was only $0.78 \%$ on May 14 (COVID-19 vaccine doses administered per 100 people, n.d.).

Meanwhile, countries with a high vaccination rate still have a high prevalence rate of COVID-19. One explanation is that SARS-CoV-2 has a breakthrough effect against vaccines (CDC \& CDC, 2021). Of note, inadequate vaccines did not completely halt Taiwan's success. This means that vaccination will lead to positive health outcomes, but it does not represent the entirety of methods to combat COVID-19. At present, a highly effective second-generation vaccine is unavailable.

\section{Conclusion}

The Taiwan model has proved capable of containing COVID-19 even at the height of an outbreak. Successful measures in disease control include border control, effective contact tracing by high medical accessibility, the use of technology, and strict quarantine or isolation policies. Two other pillars of anti-epidemic measures are the CECC and the cooperation of citizens. The Taiwan model succeeded again in containing a COVID-19 outbreak only through level 3 alert without imposing lockdown. This model may help other countries on how to design better models for containing the COVID-19 outbreak or other emerging respiratory infectious diseases.

\section{References}

Cascella, M., Rajnik, M., Aleem, A., Dulebohn, S. C., \& Di Napoli, R. (2021). Features, Evaluation, and Treatment of Coronavirus (COVID-19). PubMed; StatPearls Publishing. Retrieved from 
https://www.ncbi.nlm.nih.gov/books/NBK554776/?fbclid=IwAR0oZTfEMMLJgQboUst33jsj35HWQvxph wGsmeTb_NBtvOOoLPRDZxt1fp0

CDC. (2020, February 11). Coronavirus Disease 2019 (COVID-19). Centers for Disease Control and Prevention. cdc.gov/coronavirus/2019-ncov/vaccines/index.html

CDC, \& CDC. (2021, November 10). COVID-19 Vaccine Effectiveness. Centers for Disease Control and Prevention. Retrieved from https://www.cdc.gov/coronavirus/2019-ncov/vaccines/effectiveness/index.html?CDC_AA_refVal=https\%3 A\%2F\%2Fwww.cdc.gov\%2Fvaccines\%2Fcovid-19\%2Fhealth-departments\%2Fbreakthrough-cases.html

CECC adjusts quarantine measures for flight crews of Taiwanese airlines aboard flights arriving in Taiwan to ensure their health and safety at workplace and safeguard domestic disease prevention efforts. (2021, June 14). CECC. Retrieved from https://www.cdc.gov.tw/En/Bulletin/Detail/ECRgv5HctHBAXpO924kvvQ?typeid=158

Central Health Insurance Agency. (2020, May 14). Taiwan Can Help - National Health Insurance's Contribution in Combating COVID-19. Central Health Insurance Agency. Retrieved from https://covid19.mohw.gov.tw/en/cp-4778-53691-206.html

Chang, I-wei. J. (2020, November 10). Taiwan's Model for Combating COVID-19: A Small Island with Big Data. Middle East $\quad$ Institute. $\quad$ Retrieved from https://www.mei.edu/publications/taiwans-model-combating-covid-19-small-island-big-data

Chief Accounting Office of the Executive Yuan. (2005, February 1). Retrieved from https://www.dgbas.gov.tw/pointlist.asp?fbclid=IwAR0HtkKZXhEgSt198A2zvvtaLaGaJ2Lnh0LHFM_twA 0v6OTuFo9tS_QcZKQ

China Times News. (2021, June 10). After watching the Tsai government polls, the media actually named him: Chen Shizhong is useless-Politics. China Times News. https://www.chinatimes.com/realtimenews/20210601006570-260407?fbclid=IwAR1f5zDEri8iGhVc_3qbP 4N7vNQ-y7C-j1QS2j9uoEUYcBs_JOThya8gOew\&chdtv

COVID-19 - Taiwan. (n. d.). Sites.google.com. Retrieved October 17, 2021, from https://sites.google.com/cdc.gov.tw/2019ncov/taiwan

COVID-19 Map. (n.d.). Johns Hopkins Coronavirus Resource Center. Retrieved November 14, 2021, from https://coronavirus.jhu.edu/map.html?fbclid=IwAR1uRqO9OTKevw0aF5jC9xLgkeOaC1JzFzH5A1Dhgf3 44tIJBMwdSBrBYwI

COVID-19 vaccine doses administered per 100 people. (n. d.). Our World in Data. Retrieved November 14, 2021, from https://ourworldindata.org/grapher/covid-vaccination-doses-per-capita?time=2021-03-24..latest\&country= TWN

Crucial Policy for Combating COVID-19. (2020, May 14). Ministry of Health and Welfare. Retrieved from https://covid19.mohw.gov.tw/en/sp-timeline0-206.html

Global anti-epidemic "myth shattered" How did Taiwan's epidemic get to where it is today? (2021, May 25). BBC News. Retrieved from https://www.bbc.com/zhongwen/trad/57187804

Hongji, Y. (2021, May 31). Yang Hongji's Views" Wrong Wrong Wrong! Three mistakes in a row Taiwan's "epidemic prevention myth" shattered overnight. Newtalk; Newtalk. https://newtalk.tw/news/view/amp/2021-05-31/582146?fbclid=IwAR1oRdc0oCh-z-jEArfYnNA5y4SP0MQ 7WF5GWTNEB5XFuUsifYNj50bCydA

Hu, B., Guo, H., Zhou, P., \& Shi, Z.-L. (2020). Characteristics of SARS-CoV-2 and COVID-19. Nature Reviews Microbiology, 19, 1-14. https://doi.org/10.1038/s41579-020-00459-7

In the case of China Airlines, 1 pilot and 1 flight attendant were diagnosed/flew to the United States in mid-to-late April, and became ill after censorship 2. Pilots hit the first dose of AZ on 4/22. (2021, May 5). Liberty Times Net. https://news.ltn.com.tw/amp/news/focus/paper/1446962

Kao, D., Shih, S., Lee, S., \& Huang, I. (2021, May 17). LIVE | Tracking Taiwan's COVID-19 Outbreak: The Latest News from Taiwan's 22 Counties at a Glance | CommonWealth Magazine. LIVE | Tracking Taiwan's COVID-19 Outbreak | CommonWealth Magazine. Retrieved from https://web.cw.com.tw/covid-live-updates-2021-en/index.html 
Kao, D., Shuhua, S., Yuxin, L., \& Ningning, Z. (2021, April 28). Live Update Novotel China Airlines Group Latest Development / Common World Magazine. Real-Time Update Novotel China Airlines Group Latest Development | Interactive Topics | Common World Magazine. Retrieved from https://web.cw.com.tw/china-airlines-covid19/index.html

Kao, D., Shuhua, S., Yuxin, L., Yuting, H., Ningning, Z., \& Yingyu, C. (2021, May 17). Constantly updated "The latest developments of the epidemic situation in Taiwan: the current situation of 22 counties and cities, and the progress of vaccines at once / Common World Magazine. Constantly Updated "Taiwan Epidemic Latest Development | Interactive Topics | Common World Magazine. https://web.cw.com.tw/covid-live-updates-2021/index.html

Lee, I-chia. (2021, May 20). Alert raised to level 3 for whole nation - Taipei Times. Retrieved from https://www.taipeitimes.com/News/front/archives/2021/05/20/2003757716?fbclid=IwAR2SRj9WXKGEW VGZsnleHDG6wtLjc5qq_Ugeg3YkFZslxG612tJtvGo5CZM

Ministry of Health and Welfare. (2020a, May 14). Safeguarding the community line of defense to create a positive new lifestyle for disease prevention. Ministry of Health and Welfare. https://covid19.mohw.gov.tw/en/cp-4786-53904-206.html

Ministry of Health and Welfare. (2020b, December 1). Fall-winter COVID-19 prevention program to be launched on December 1; CECC urges the public and healthcare facilities to follow related measures. Disease Control Agency. Retrieved from https://covid19.mohw.gov.tw/en/cp-4868-56853-206.html

Ministry of Health and Welfare. (2021, July 2). In response to spread of Delta variant globally, Taiwan to tighten health monitoring measures for people entering Taiwan via airport/port starting 12:00 pm on July 2. Disease Control Agency. Retrieved from https://covid19.mohw.gov.tw/en/cp-4868-62643-206.html

National Current Affairs Polls. (2020, December 18). Retrieved from https://www.dpp.org.tw/upload/news/2020-12-21_2020\%E5\%8F\%B0\%E7\%81\%A3\%E7\%B8\%BD\%E9\% AB\%94\%E8\%A1\%A8\%E7\%8F\%BE\%E6\%B0\%91\%E8\%AA\%BF\%E8\%A1\%A8\%E6\%A0\%BC.pdf?fbcli d=IwAR21eldSX71uUG7wI73z82hcMSGM1FWj_JcpEEzDrFR7Z6W1_cw93xcZza0

News, T. (2021a, May 12). Taiwan reports record 16 local COVID cases in one day | Taiwan News | 2021-05-12 21:40:00. Taiwan News. from https://www.taiwannews.com.tw/en/news/4201562?fbclid=IwAR0gPks2bQFfDkXr1hlKCR-zYVhmRt3iKI i3zwJh9XN6gCvpy3RTkEUmRgM

News, T. (2021b, May 14). Taiwan's 4 epidemic warning levels | Taiwan News | 2021-05-14 16:47:00. Taiwan News. Retrieved from https://www.taiwannews.com.tw/en/news/4203460

News, T. (2021c, May 19). Taiwan launches new QR code for real-name registration system | Taiwan News | 2021-05-19 14:02:00. Taiwan News. Retrieved from https://www.taiwannews.com.tw/en/news/4206312

Quarantine System for Entry (Aircraft version)-Ministry of Health and Welfare. (n. d.). Hdhq.mohw.gov.tw. Retrieved November 14, 2021, from https://hdhq.mohw.gov.tw/Default1 ?openExternalBrowser=1\&fbclid=IwAR2LInHwTrwVes16_oq-vslqHve DOKESoQdASARDIHKygoU7GYmZ13AHDiE

Straight to the point of care. (2021). Retrieved from https://bestpractice.bmj.com/topics/en-us/3000168/pdf/3000168/Coronavirus\%20disease\%202019\%20\%28 COVID-19\%29.pdf

Taiwan Stock Exchange FACT BOOK 2021. (n. d.). Retrieved October 17, 2021, from www.twse.com.tw/downloads/zh/about/company/factbook/2021/0.00.html?fbclid=IwAR277B6ggBkOM5B BcAT3SXqN8IpkgzPSwTU_E7Z_md9usF-EX4_kuKQr3ws

Tan, Y. (2021, May 19). Covid-19: What went wrong in Singapore and Taiwan? BBC News. Retrieved from https://www.bbc.com/news/world-asia-57153195?fbclid=IwAR1hBNXaJpBOZb14JMepXrZm65NfG8gPV 9hRdPIJFfT6MBacna6eSrCDzmg

They are all British variants! The command center confirms that the Novotel cluster is related to the infection of China Airlines pilots. (2021, May 1). Liberty Times Net; Liberty Times Net. https://news.ltn.com.tw/amp/news/life/breakingnews/3517720?fbclid=IwAR3z8fzAoB_lBUGqBsg0rmzg6r xezlFShdInp6a1_1QqaBdEjNp2u6b0KkE

Tracking SARS-CoV-2 variants. (n. d.). Retrieved November 14, 2021, from 
https://www.who.int/en/activities/tracking-SARS-CoV-2-variants/?fbclid=IwAR1scP3JecishBL1XC5LqMC Dty3VFyhyaeLakpHj3jmkbOabj8rVSycWPi0

Weinstein, B. (2021, June 1). How Strong Was Taiwan's COVID Response? Quillette. Retrieved from https://quillette.com/2021/06/01/taiwans-covid-response-what-went-wrong/?fbclid=IwAR0w0r0cS_4CNzS 2w59T_QX0irFYCk1GHCP0g1ljQDZcsqeTMrqc0LWnbe8

Wu, C., \& Wu, K. C. (2020, September 9). Response to the Coronavirus Disease-2019 Pandemic: Lessons Learned from the Taiwan Model. Asian Social Science. http://dx.doi.org/10.5539/ass.v16n10p16

\section{Copyrights}

Copyright for this article is retained by the author(s), with first publication rights granted to the journal.

This is an open-access article distributed under the terms and conditions of the Creative Commons Attribution license (http://creativecommons.org/licenses/by/4.0/). 